\title{
Estimating numbers of embryonic lethals in conifers
}

\author{
OUTI SAVOLAINEN, KATRI KÄRKKÄINEN \& HELMI KUITTINEN* \\ Department of Genetics, University of Oulu, Oulu, Finland and *Department of Genetics, University of Helsinki, \\ Helsinki, Finland
}

\begin{abstract}
Conifers have recessive lethal genes that eliminate most selfed embryos during seed development. It has been estimated that Scots pine has, on average, nine recessive lethals which act during seed development. Such high numbers are not consistent with the level of outcrossing, about 0.9-0.95, which has been observed in natural populations. Correcting for environmental mortality or using partial selfings provides significantly lower estimates of lethals. A similar discordance with numbers of lethals and observed outcrossing rates is true for other species.
\end{abstract}

Keywords: embryonic lethals, inbreeding depression, outcrossing, Pinus sylvestris, Picea omorika.

\section{Introduction}

Conifers have no self-incompatibility mechanisms but early-acting inbreeding depression eliminates selfed embryos before seed maturation (Sarvas, 1962; Hagman \& Mikkola, 1963). A genetic model for this inbreeding depression has been developed by Koski (1971) and Bramlett \& Popham (1971). Koski (1971, 1973) has estimated that Pinus sylvestris and Picea abies have on average nine and 10 recessive lethals, respectively, which should eliminate about 90 per cent of the selfed embryos, and result in outcrossing rates very close to 1.0 at the mature seed level. However, estimates based on genetic markers result in outcrossing rates of 0.9 0.95 (see Muona, 1989 for review). This is clearly lower than predicted by the embryonic lethals models.

We examine the nature of the embryonic lethals models, using Pinus sylvestris L. and Picea omorika Pancic (Purk.) as example species. Our results suggest that the simplest model considerably overestimates the number of lethals and that revised estimates of lethal numbers are more consistent with the observed outcrossing rates. The proportion of selfed seed after partial selfings and crossings provides robust estimates of lethal numbers.

Correspondence: Outi Savolainen, Department of Genetics, University of Oulu, SF-90570 Oulu, Finland.

\section{Reproduction system of conifers}

The proportion of self-pollination in conifers is variable. Sarvas (1962) suggested an average of 26 per cent for Pinus sylvestris, while Koski (1970) estimated values of self-fertilization around 10 per cent. The genera Pinus and Picea have polyzygotic polyembryony, i.e. the ovules contain several archegonia. In Pinus sylvestris, the most common number of archegonia is two but it can range from one to five. All egg cells within the ovule have the same genotype. These are fertilized by different pollen grains. Only one of these embryos develops to form a mature embryo in the seed (see Sorensen, 1982). If all embryos within the ovule die during development, an empty seed will result. The proportion of empty seed is on average 12 per cent for Pinus sylvestris after open pollination (Koski, 1971). Upon complete selfing, the empty seed frequencies are much higher, on average 84 per cent (Koski, 1971). In Pinus, all empty seeds are due to embryonic deaths, as non-pollinated ovules do not form seeds. In Picea, unfertilized ovules may develop into empty seeds. Embryonic deaths due to the environment also result in empty seeds. Especially in Picea, empty seed frequencies upon outcrossing can be high.

\section{The model}

Koski (1971), Bramlett \& Popham (1971), and Lindgren (1975) have modelled the action of the early acting recessive lethals genes. The simple models assume 
they are independent, later models have assumed interaction (Griffin \& Lindgren, 1985). Bramlett \& Bridgwater (1976) found support for independently acting lethals in Pinus virginiana. Such loci can be mapped based on aberrant segregation ratios (e.g. Hedrick \& Muona, 1990), but little is known about their function. Our approach is based on slightly modifying the basic models of Bramlett \& Popham (1971), Koski (1971), and Lindgren (1975). A filled seed will be formed from an ovule where at least one embryo survives. The number of polyzygotic embryos in the ovule is denoted by $k$. A parental tree is heterozygous at $n$ loci for recessive embryonic lethals. If, following self-fertilization, an embryo is homozygous for a lethal gene, it will die. It is assumed that a proportion $d$ of both selfed and outcrossed embryos die due to changes in the environment. Koski (1971) assumed that deaths after outcrossing are due to genetic causes. This leads to unrealistically high frequencies of lethals at individual loci (about 0.1 ). Given mutation rates of $10^{-5}$ to $10^{-6}$, such a model would require overdominance at the individual loci. Namkoong \& Bishir (1987) considered a mutation-selection model, which suggests that the number of potentially lethal loci must be much higher, maybe 10,000 . If each individual tree contains on average about 10 lethals, the probability of shared lethals between unrelated trees is very low. Furthermore, Bishir \& Namkoong (1987) estimated that the environmental mortality for Pinus taeda and Pinus virginiana was $5-30$ per cent. We regard the mortality after crossing as environmental. Here we choose to consider the environmental mortality per individual embryo (not seed) because the genetic mortality also occurs on an embryo basis. If more than one embryo survives, only one will develop into a mature seed. The outcome of this will be by chance.

The probability that all embryos die of genetic causes upon selfing, given $n$ embryonic lethals and $k$ archegonia per ovule, is

$P(k)=1 /\left(2^{n}\right) \Sigma\left(\begin{array}{l}n \\ r\end{array}\right)\left(1-(1 / 2)^{r}\right)^{k}$,

where $r$ is the number of loci where the female gamete has a lethal allele. The probability that a male gamete carries a lethal at least one of those loci is $\left(1-1 / 2^{r}\right)$. If there are two embryos, both male gametes carry lethals with probability $\left(1-1 / 2^{r / 2}\right.$. The probability that one of the male gametes carries a lethal and the other one does not is $2\left(1-1 / 2^{r}\right)\left(1 / 2^{r}\right)$, and that neither does is $\left(1 / 2^{r}\right)^{2}$. This could be extended for the three archegonia case but we will consider at most two archegonia for simplicity's sake. The embryos within an ovule are not independent random samples of all embryos in the tree, as was presumed by Sorensen (1982). All egg nuclei in an ovule share the same genotype, i.e. have the same number of embryonic lethals in the haploid genome. The probability of genetic death for these embryos depends on this number, which varies between ovules within a tree (Lindgren, 1975).

After mixed pollination, we obtain the proportion of empty seed and the proportion of outcrossed seed among sound seed following Lindgren (1975), Koski (1982), and Koski \& Muona (1986). The present model differs by incorporating the environmental death of selfed embryos. In the following:

$E=$ expected frequency of empty seed,

$s=$ frequency of selfed seed among sound seed,

$c=$ proportion of cross pollen,

$d=$ probability of death of an embryo due to environmental causes,

$P(1)=$ probability of genetic death of a single selfed embryo,

$P(11)=$ probability that two selfed embryos die of genetic causes,

$P(12)=$ probability that one selfed embryo dies of lethals, the other selfed embryo does not, and

$P(22)=$ neither selfed embryo dies of genetic causes.

When $k=1$

$E=(1-c)[P(1)+(1-P(1)) d]+c d$

$s=(1-c)(1-P(1)(1-d)) /(1-E)$

for $k=2$

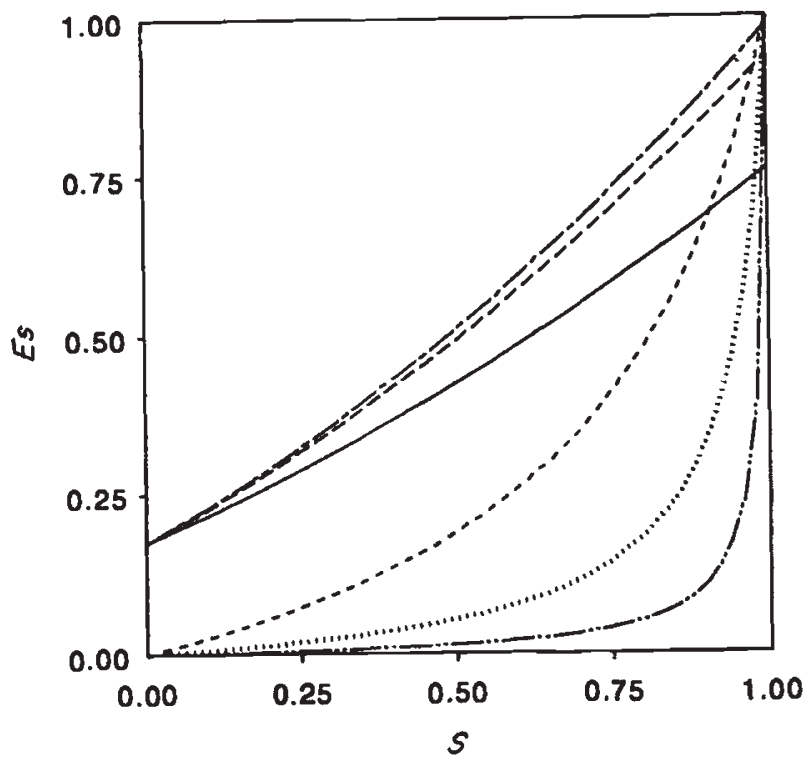

Fig. 1 Predictions of empty seed frequency $(E)$ and proportion of selfed seed $(s)$ given different numbers of lethals $(n)$, and different proportions of self pollen $(S)$ with environmental mortality $d=0.3 .(\longrightarrow) E(n=5),(---) s(n=5)$, $(-\cdots) E(n=10),(\cdots) s(n=10),(-\cdots) E(n=15)$, $(-.-) s(n=15)$. 


$$
\begin{aligned}
E= & (1-c)^{2}\left(P(11)+P(12) d+P(22) d^{2}\right) \\
& +2 c(1-c)\left[(P(1)+(1-P(1)) d] d+c^{2} d^{2}\right. \\
s= & \left\{(1-c)^{2}\left[P(22)\left(1-d^{2}\right)+P(12)(1-d)\right]\right. \\
& +2 c(1-c)((1-P(1)) d((1-d) \\
& \left.\left.+0.5(1-P(1))(1-d)^{2}\right]\right\} /(1-E) .
\end{aligned}
$$

The frequencies of Pinus sylvestris ovules with one, two and three embryos are $0.4,0.5$, and 0.1 (Sarvas, 1962). In all our computations, we weighted the results for the one and two ovule cases with 0.4 and 0.6 . We used the same weightings for both Pinus sylvestris and Picea omorika. Figure 1 shows examples of the predictions of the model for both $E$ and $s$ for three different values of $n$, with environmental mortality 0.3 . The empty seed percentages upon complete selfing vary between 80 per cent and close to 100 per cent for these values of $n$. These frequencies are sensitive to environmental variation (Fig. 2). The predictions for proportions of selfed seed depend strongly on the lethal numbers. As opposed to empty seed frequencies, the proportions of selfed seed in the partial crossings are quite insensitive to variation in environmental mortality, as both classes of seed are equally influenced by this source of mortality (Fig. 2).

\section{Materials and methods}

Pinus sylvestris is known as a highly self-infertile species (Koski, 1971), Picea omorika, however, has been reported to be highly self-fertile (Langner, 1959; Koski, 1973; Kuittinen \& Savolainen, 1992).

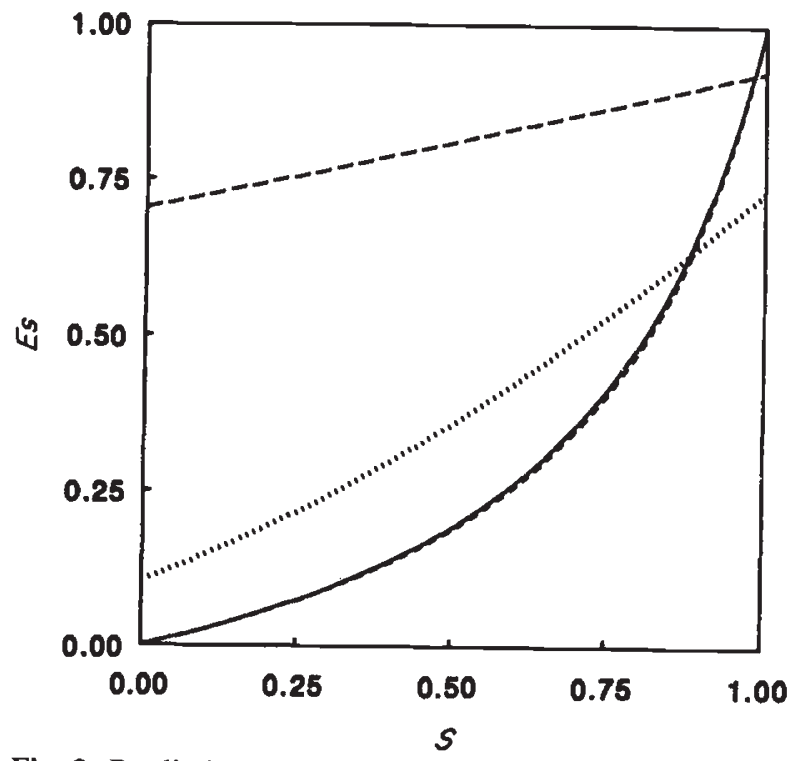

Fig. 2 Predictions for $E$ and $s$ with five lethals and two levels of environmental mortality, $d=0.2$ and $d=0.8$. (-- - ) $E(d=0.8),(\longrightarrow) s(d=0.8),(\cdots) E(d=0.2),(\cdots)$ $s(d=0.2)$.
Crosses with Pinus sylvestris were made at the Punkaharju Tree Breeding station in the spring of 1985. We chose three maternal genotypes, listed as E719, E708, and P251 by the Finnish Forest Research Institute. Based on earlier data by Koski (1971 and personal communication), these genotypes were known to vary widely in the empty seed frequencies upon complete selfing. The genotypes for the foreign pollen mixes were chosen in such a way that outcrosses and selfs could be unambiguously distinguished based on their genotypes at some enzyme loci. None of the paternal genotypes originate from close to the maternal genotype. For crosses with E708, a mix of pollen from clones E706 and E720 was used, for genotype E719 a mix of E706, E720, and E726, and for P251, a mix of E711, E718, and E719D. Pollen from different sources was mixed in equal volumes. The proportion of cross pollen (c) was $0,25,50,75$ or 100 per cent. Cones were harvested in the autumn of 1986.

The Picea omorika crosses were made in the arboretum of the Finnish Forest Research Institute in Punkaharju in the spring of 1988 (see Kuittinen \& Savolainen, 1992). Two trees were chosen, 1114 and 1795 in the listing of the Forest Research Institute. Genotypes for the foreign pollen mixes were chosen based on their enzyme genotypes. The foreign mixes contained pollen from seven trees. Female flowering in this year was poor, and there were not enough female strobili to conduct the whole set of pollinations. Thus, the proportion of foreign pollen in the crosses (c) was 0,50 or 100 per cent. The cones and seeds were harvested in the autumn of 1988 .

Mature seeds were $\mathrm{X}$-rayed to classify them as empty or filled. If the endosperm was fully developed, they were classified as filled (e.g. Griffin \& Lindgren, $1985)$. Samples of about 100 seeds were examined per cross for Pinus sylvestris, for Picea omorika the sample sizes varied between 207 and 779 .

The proportion of outcrosses among filled seed was estimated by determining the genotypes of the embryos at the diagnostic loci. Electrophoretic procedures were as described by Muona et al.(1987).

\section{Estimating numbers of lethals}

We used four different methods to estimate the numbers of lethals. First we followed the method of Koski (1971, 1973), which is based on empty seed proportion upon complete selfing, where all deaths are regarded as genetic. We used the average of all the available empty seed frequencies and obtained the estimates of $n$ as did Koski (1971).

Secondly, we corrected the empty seed frequencies by assuming that there is an environmental component. 
Instead of $E$, we used $E^{\prime}=\left(E_{\mathrm{s}}-E_{\mathrm{c}}\right) /\left(1-E_{\mathrm{c}}\right)$, where $E_{\mathrm{s}}$ and $E_{\mathrm{c}}$ are the empty seed frequencies upon complete selfing and complete outcrossing, respectively, as has been suggested by Lindgren (1975). A similar estimation method was suggested by Bishir \& Namkoong (1987). We then applied the model of Koski (1971) to these corrected values.

Thirdly, we used the classical method of Morton et al. (1956), which has been used earlier by Sorenson (1969) and Franklin (1972). The zygote load is estimated as $2 \mathrm{~B}=-4$ In $R$, where $R$ is the relative fertility of the selfs, $\left(1-E_{\mathrm{s}}\right) /\left(1-E_{\mathrm{c}}\right)$.

Fourthly, we compared the results of partial selfings to the predictions of the model, given different numbers of lethals. An initial estimate of $d$ was obtained from the empty seed frequency upon complete outcrossing. The estimation equation for Pinus sylvestris is $0.6 d^{2}+0.4 d-E=0$, where $d$ is the environmental mortality per embryo and $E$ is the observed empty seed frequency in 1986, the year when the crosses were made. We then chose the $n$ whose respective curve fitted the data points best.

These methods differ with respect to how they handle the environmental death of seeds and polyembryony. The environmental mortality is especially important for spruces and other genera where unpollinated ovules may develop into seeds, and thus many seeds may be empty for other than genetic reasons. The first model ignores this problem. The second model takes both factors into account. The third model ignores polyembryony. Estimation of lethal number from crosses tries to side-step environmental mortality.

\section{Results}

Empty seed data upon selfing were available from our crosses and from selfings of these clones by Koski (Table 1). The clones P251, E708 and E719 had aver-

Table 1 Empty seed frequencies upon selfing $\left(E_{\mathrm{s}}\right)$ and controlled outcrossing $\left(E_{\mathrm{c}}\right)$ and estimated numbers of lethals with different methods, (1) based on Koski (1971), (2) Lindgren (1975), (3) Morton et al. (1956) and (4) partial crosses for Pinus sylvestris trees P251, E708, and E719 and Picea omorika trees 1114 and 1175

\begin{tabular}{lrrrrrr}
\hline \multicolumn{1}{c}{$E_{\mathrm{s}}$} & $E_{\mathrm{c}}$ & 1 & 2 & 3 & 4 \\
\hline $\begin{array}{l}\text { P. sylvestris } \\
\text { P251 }\end{array}$ & & & & & \\
E708 & 83.7 & 15 & 4 & 4 & 3.4 & 3 \\
E719 & 98.5 & 12 & 7 & 7 & 6.7 & 3 \\
$\begin{array}{l}\text { P. omorika } \\
1114\end{array}$ & 94.2 & 85 & 11 & 4 & 3.9 & 3 \\
1795 & 94.8 & 80 & 11 & 5 & 5.3 & 5 \\
\hline
\end{tabular}

age empty seed frequencies based on 3, 3, and 2 years, respectively. The method of Koski (1971) led to the estimates of number of heterozygous lethals of 4,7 , and 16 (Table 1). Both trees for Picea omorika were found to have 11 lethals (see Table 1).

Following Lindgren (1975), we then corrected the empty seed frequencies with those from controlled outcrossing. The estimates of lethal numbers were lower than the first estimates for those trees where the complete outcrossings had high empty seed frequencies.

The classical method of Morton et al. (1956) gave the same average number of lethals as the method of Lindgren (1975).

The results of fitting curves with different $n$ values to the results after partial selfings are presented for each tree in Figs 3-7. The figures for Pinus sylvestris contain curves for two values of $n$, one based on the genetic Koski (1971) estimate, the other on the one we found to be the best fit. The results on partial crossings provided slightly lower estimates for lethal numbers than the other two methods, which consider environmental mortality. The observed and predicted proportions of inbreds for other proportions of self pollen agree in Pinus sylvestris, where we have several data points available.

Ignoring environmental mortality seriously overestimates the number of lethals. The importance of this depends on the level of environmental mortality, which can vary widely between crosses. Our estimates of $d$ for Scots pine varied from 22 to 81 per cent, for $P$.

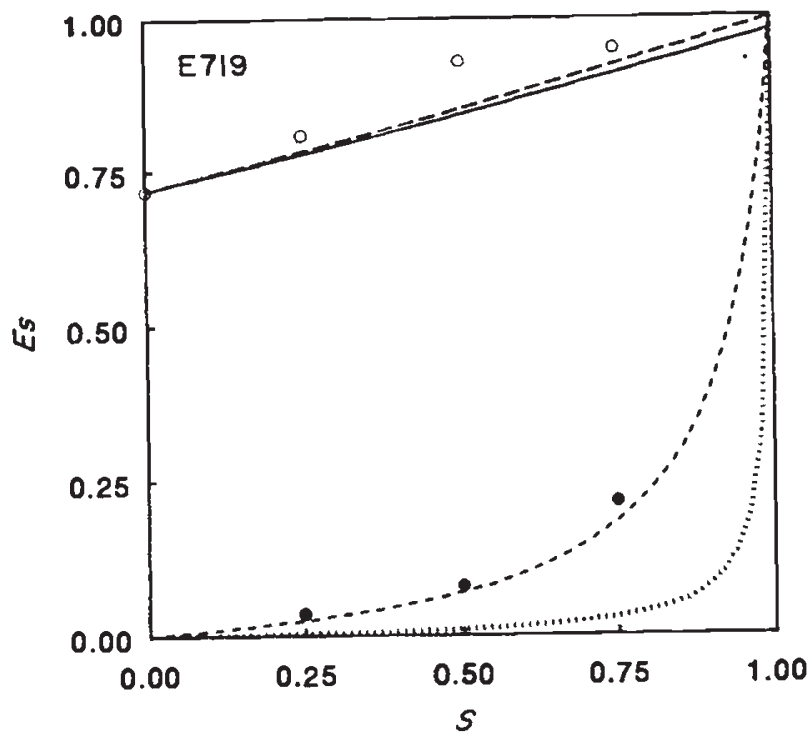

Fig. 3 Predictions for $E$ and $s$, given the estimates of lethal numbers based on methods (1) and (4) of Table 1, and observed values for Pinus sylvestris E719. $d=0.81 .(-$ $E(n=9),(--) s(n=9),(----) E(n=16),(\cdots) s(n=16)$, (0) E(observed), (•) s(observed). 


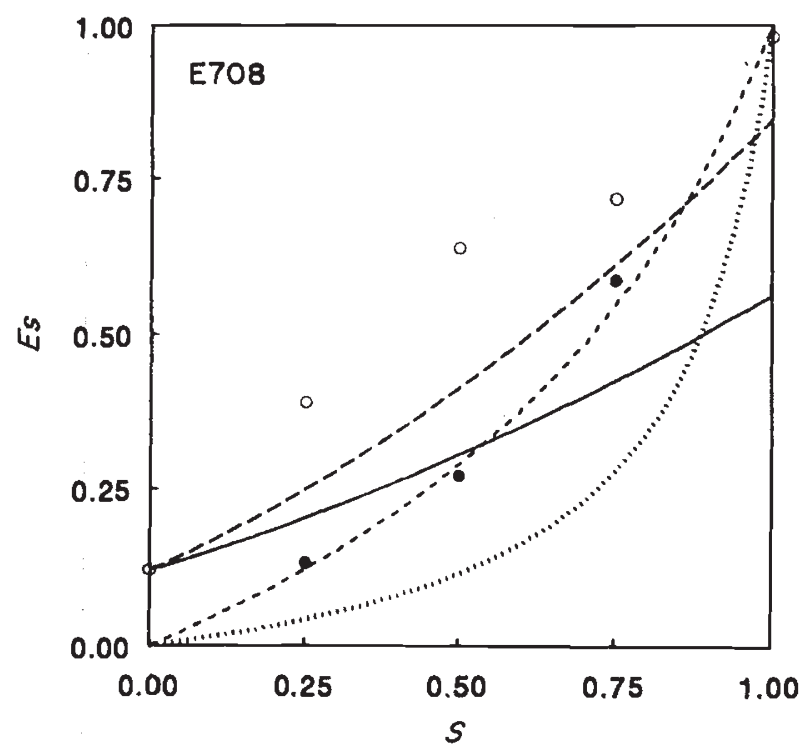

Fig. 4 Predictions for $E$ and $s$, given the estimates of lethal numbers based on methods (1) and (4) of Table 1, and observed values for Pinus sylvestris E708. $d=0.22$. $(-) E(n=3),(\cdots) s(n=3),(-\cdots-) E(n=7),(\cdots)$ $s(n=7),(0) E($ observed $),(\bullet) s($ observed $)$.

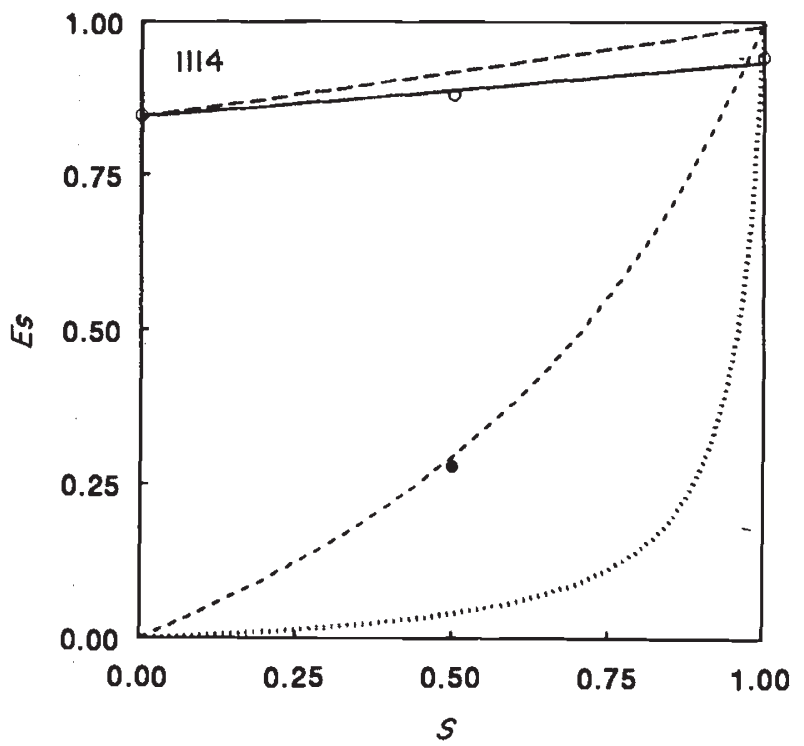

Fig. 6 Predictions for $E$ and $s$, given the estimates of lethal numbers based on methods (1) and (4) of Table 1, and observed values for Picea omorika 1114. $d=0.90$. $(-) E(n=3),(---) s(n=3),(---) E(n=11),(\cdots)$ $s(n=7),(0) E($ observed $),(\bullet) s($ observed $)$.

omorika estimates of $d$ were 0.90 and 0.87 . The overestimation is especially serious in Picea, where empty seed frequencies are higher than in Pinus as a rule, because ovules with no embryo can develop into seeds.

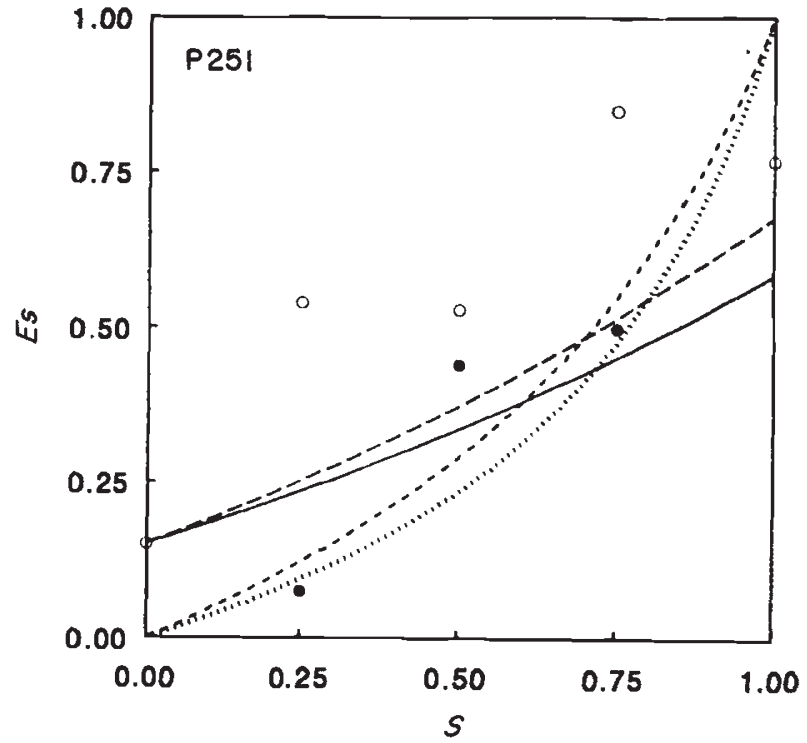

Fig. 5 Predictions for $E$ and $s$, given the estimates of lethal numbers based on methods (1) and (4) of Table 1, and observed values for Pinus sylvestris P251. $d=0.27$. $(-) E(n=3),(---) s(n=3),(---) E(n=4),(\cdots)$ $s(n=4),(0) E($ observed $),(\bullet) s($ observed $)$.

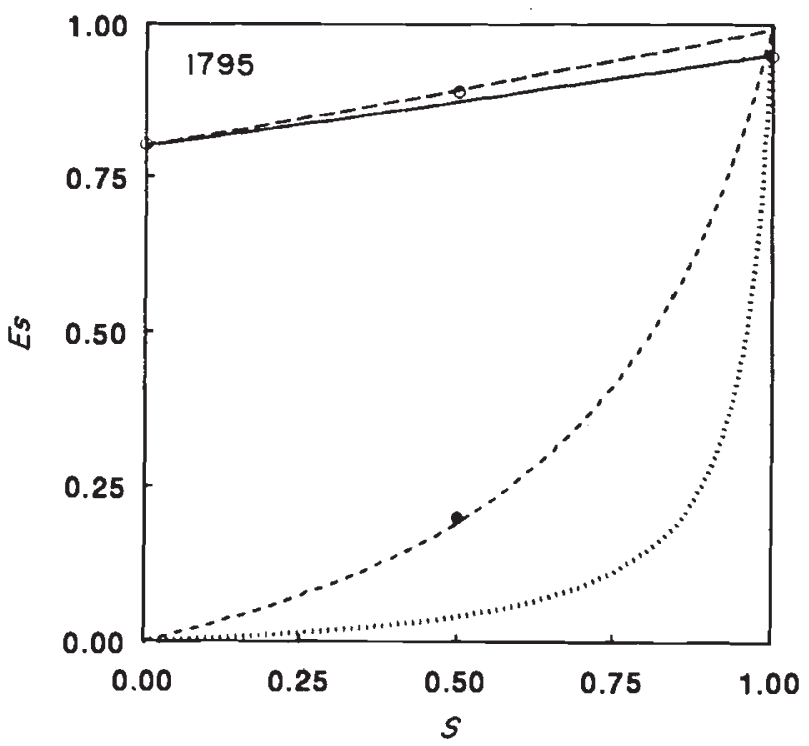

Fig. 7 Predictions for $E$ and $s$, given the estimates of lethal numbers based on methods (1) and (4) of Table 1, and observed values for Picea omorika 1795. $d=0.87$. $(-) E(n=5),(---) s(n=5),(---) E(n=11),(\cdots)$ $s(n=11),(0) E$ (observed), $(\bullet) s$ (observed).

One Pinus sylvestris had an especially high empty seed frequency after crossing and selfing. This was probably due to environmental effects specific to that one maternal genotype. 


\section{Discussion}

The basic genetic method (Bramlett \& Popham, 1971; Koski, 1971) has been long known to overestimate the number of lethals (e.g. Koski, 1982). The Koski (1971) method was modified by Bishir \& Pepper (1977) to take into account the variation in the number of fertilizations, but this had only a minor influence on the esimates. Lindgren (1975) and Bishir \& Namkoong (1987) considered environmental mortality. Bishir \& Namkoong (1987) found that the estimates of the number of lethals were reduced only by one in their dataset, if environmental mortality was considered. For the present data, environmental mortalities were higher, and the correction resulted in a much larger effect.

Empty seed frequencies upon selfing alone are clearly inadequate for estimating lethal numbers, they should be accompanied by results on complete outcrossing, against which inbreeding depression can be measured (e.g. Charlesworth \& Charlesworth, 1987).

The method of Morton et al. (1956) ignores polyembryony, and should thus yield conservative estimates compared to those methods that take it into account, as noted by Ledig (1986). However, the effect is small compared to the relative effect of environmental mortality. The expected relative magnitudes of the effects of ignoring polyembryony and environmental mortality can be deduced from Fig. 1 of Koski (1971).

Partial selfings was an accurate method of estimating numbers of lethals in conifers. This method is quite robust with respect to the rate of environmental mortality. In our small dataset, the reduction from the Koski (1971) estimates to the partial crossings estimates was considerable, from nine on average to five. The estimates were also somewhat lower than the other two methods yielded. However, in addition to estimates of lethal numbers, the crosses provide some test of the model when several degrees of partial crossing are used. The data fitted the general shape of the curve predicted by the model.

The outcrossing rates with efficient multilocus estimation methods for species like Pinus sylvestris and Picea abies have often been found to be about 0.90 . The proportion of the tree's own pollen in pollination may vary, but 25 per cent seems to be a reasonable esimate. Given this and previously published values of about nine lethals on average, the outcrossing rate should never be less than about 0.98 . The outcrossing estimates in natural populations cannot be reconciled with so many lethals. About 25 per cent of self-pollination and 90-92 per cent outcrossing is consistent with five or six lethals on average. The number of lethals must have been overestimated when only empty seed frequencies were used, as demonstrated above. Our small dataset is not sufficient to evaluate by how much the estimate of nine lethals on average in Pinus sylvestris should be reduced.

Estimates of lethal numbers and outcrossing rates are available for several conifer species (reviews and references in Ledig, 1986; Charlesworth \& Charlesworth, 1987, Muona, 1989). As Charlesworth \& Charlesworth (1987) pointed out, the proportion of filled seed upon selfing does not seem to predict the observed outcrossing rates. Species with relatively high self-fertility can have high outcrossing rates due to other mechanisms promoting outcrossing, as has been found for Picea omorika (Kuittinen \& Savolainen, 1992), but very low filled seed yields upon selfing (i.e. many lethals) are clearly not consistent with outcrossing rates much below one. One such sample is Larix laricina, for which the average outcrossing was estimated at 0.71 (Knowles et al., 1987), and which should have 11 lethals on average (Park \& Fowler, 1982). In this case, the lethal numbers were estimated with the Morton et al. (1956) method, which corrects for environmental mortality. The relative self-fertility was found to be 0.068 . There should thus be 86 per cent self-pollination to obtain 29 per cent selfed seed at the mature seed stage, which does not seem likely. Perhaps the selfs in natural populations have higher relative viability than selfs in bagged controlled crosses. Clearly, the relationship between early inbreeding depression and outcrossing rates warrants further study.

\section{Acknowledgements}

We acknowledge financial support from the National Research Council for Agriculture and Forestry and thank Anni Harju for participating in some of the laboratory work. We are grateful to the staff of the Punkaharju Tree Breeding Station for their help in conducting the crosses. Discussions on these topics with David Bramlett, Floyd Bridgwater, Veikko Koski, and Dag Lindgren have not led to deleterious depression, quite the opposite.

\section{References}

BISHIR, J. AND NAMKOONG, G. 1987. Unsound seeds in conifers: estimation of numbers of lethal alleles and of magnitudes of effects associated with the maternal parent. Silvae Genet., 36, 180-185.

BISHIR, J. AND PEPPER, D. W. 1977. Estimation of numbers of embryonic lethal alleles in conifers. 1. Self-pollinated seed. Silvae Genet., 26, 50-54. 
BRAMLETT, D. AND BRIDGWATER, F. E. 1976. Segregation of recessive embryonic lethal alleles in a $F_{1}$ population of Virginia pine. In: Proceedings of the IUFRO Conference on Breeding Theory, Progeny Testing and Seed Orchards. Williamsburg, VI, pp. 401-409.

BRAMLETT, D. AND POPHAM, T. w. 1971. Model relating unsound seed and embryonic lethal alleles in self-pollinated pines. Silvae Genet., 20, 192-193.

CHARLESWORTH, D. AND CHARLESWORTH, B. 1987. Inbreeding depression and its evolutionary consequences. Ann. Rev. Ecol. Syst., 18, 237-268.

FRANKLIN, E. C. 1972. Genetic load in loblolly pine. Am. Nat., 106, 262-265.

GRIFFIN, A. R. AND LINDGREN, D. 1985. Effect of inbreeding on production of filled seed in Pinus radiata - experimental results and a model of gene action. Theor. Appl. Genet., 71, 334-343.

HAGMAN, M. AND MIKKOLA, L. 1963. Observations on cross-, self- and interspecific pollinations in Pinus peuce. Silvae Genet., 12, 73-79.

HEDRICK, P. W. AND MUONA, O. 1990. Linkage of viability genes to marker loci in selfing organisms. Heredity, 64, 67-72.

KNOWLES, P., FURNIER, G. R., ALEKSIUK, M. A. AND PERRY, D. J. 1987. Significant levels of self-fertilization in natural populations of tamarack. Can.J. Bot., 65, 1087-1091.

KoskI, v. 1970. A study of pollen dispersal as a mechanism of gene flow in conifers. Commun. Inst. For. Fenn., 70, 1-78.

Koski, v. 1971. Embryonic lethals of Picea abies and Pinus sylvestris. Commun. Inst. For. Fenn., 75, 1-30.

KOSKI, v. 1973. On self-pollination, genetic load and subsequent inbreeding in some conifers. Commun. Inst. For. Fenn. 78, 1-42.

KoskI, v. 1982. How to study the rate of inbreeding in populations of Pinus sylvestris and Picea abies. Silva Fenn., 16, 83-87.

KOSKI, V. AND MUONA, O. 1986. Probability of inbreeding in relation to clonal differences in male flowering and embryonic lethals. In: Proceedings of the IUFRO Conference on Breeding Theory, Progeny Testing and Seed Orchards. Williamsburg, VI, pp. 391-400.
KuitTinen, H. AND SAVOlainen, o. 1992. Picea omorika is a fully self-fertile but outcrossing conifer. Heredity, 68, 183-187.

LANGNER, w. 1959. Selbstfertilität and Inzucht bei Picea omorica (Pancic) Purkyne. Silvae Genet., 8, 84-93.

LEDIG, F. T. 1986. Heterozygosity, heterosis, and fitness in outbreeding plants. In: Soulé, M. (ed.) Conservation Biology, the Science of Scarcity and Diversity. Sinauer Associates, Sunderland, MA, pp. 77-104.

LINDGREN, D. 1975. The relationship between self-fertilization, empty seeds and seeds originating from selfing as a consequence of polyembryony. Stud. Forest. Suec., 126, 1-24.

MORTON, N. E., CROW, J. G. AND H. J. MULLER, 1956. An estimate of the mutational damage in man from data on consanguineous marriages. Proc. Natl. Acad. Sci., U.S.A., 42, 855-863.

MUONA, O. 1989. Population genetics in tree improvement. In: Brown, A. H. D., Clegg, M. T., Kahler, A. L. and Weir, B.S. (eds) Plant Population Genetics, Breeding and Genetic Resources. Sinauer Associates, Sunderland, MA, pp. 282-298.

MUONA, O., YAZDANI, R. AND LINDQVisT, G. 1987. A nalysis of linkage in Picea abies. Hereditas, 106, 31-36.

NAMKOONG, G. AND BISHIR, J. 1987.The frequency of lethal alleles in forest tree populations. Evolution, 41, 11231127.

PARK, Y. S. AND FOWLER, D. P. 1982. Effects of inbreeding and genetic variances in a natural population of Tamarack (Larix decidua (Du Roi) K. Koch) in eastern Canada. Silvae Genet., 31, 21-26.

SARVAS, R. 1962. Investigations on the flowering and seed crop of Pinus sylvestris. Commun. Inst. For. Fenn., 53, 1-198.

SORENSEN, F. C. 1969. Embryonic genetic load in coastal Douglas-fir, Pseudotsuga menziesii. Am. Nat., 103, 389398.

SORENSEN, F. C. 1982. The roles of polyembryony and embryo viability in the genetic system of conifers. Evolution, 36 , 725-733.

STERN, K. AND ROCHE, L. 1974. Genetics of Forest Ecosystems. Springer-Verlag, Berlin. 